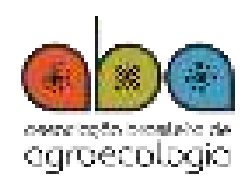

ISSN: $1980-9735$

DOI: 10.33240/rba.v15i3.23165

Vol. $15 \mid$ N $^{0} .3$ | p. $110-122$ | 2020

\title{
SABERES E PRÁTICAS TRADICIONAIS DA EXTRAÇÃO DO ÓLEO DE Carapa guianensis Aubl. (ANDIROBA) EM ÁREA DE VÁRZEA DO MUNICÍPIO DE IGARAPÉ-MIRI, PA.
}

Traditional knowledge and practice of the oil extraction of Carapa guianensis Aubl. (andiroba) in area of várzea of the Municipality of Igarapé-Miri, PA

\author{
Aline Dias Brito ${ }^{1}$, Tayse Fernanda do Amaral Silva ${ }^{2}$ \\ Roberta Fátima Rodrigues Coelho ${ }^{3}$ e Louise Ferreira Rosal ${ }^{4}$
}

\begin{abstract}
1 Engenheira Agrônoma; Mestranda em Desenvolvimento Rural Sustentável e Gestão de Empreendimento Agroalimentares - PPDRGEA - IFPA - Castanhal. E-mail: alinedbrito@outlook.com.
\end{abstract}

${ }^{2}$ Engenheira Agrônoma; Mestre em Desenvolvimento Rural Sustentável e Gestão de Empreendimento Agroalimentares - PPDRGEA - IFPA - Castanhal.

E-mail: tayse.silva17@hotmail.com

${ }^{3}$ Professora do Instituto Federal do Pará (IFPA) - Castanhal. Doutora em ciências agrarias. E-mail: rober-

ta.fatimacoelho@gmail.com.

${ }_{4}^{4}$ Professora do Instituto Federal do Pará (IFPA) - Castanhal. Doutora em Agronomia. E-mail: louiserosal@gmail.com.

Recebido em: 13/01/2020 Aceito em: 20/05/2020

Correspondência para: alinedbrito@outlook.com

\section{RESUMO}

O presente estudo objetivou descrever os processos de extração tradicional do óleo de Carapa guianensis Aubl. (andiroba) em Projetos de Assentamentos Agroextrativistas (PAEX) das várzeas do Município de Igarapé-Miri, PA. Os dados foram obtidos por meio de questionários estruturados e semiestruturado com 14 pessoas que trabalham com andiroba em 4 PAEX - ilhas Mamangal, Mutirão, Jarembú e Buçu. A extração do óleo de andiroba é realizada por 10 dos 14 entrevistados - e consiste em dois métodos artesanais: extração em superfície inclinada e no tipiti. $O$ processo de extração de óleo envolve três etapas: coleta e seleção das sementes, preparo da massa e a extração do óleo. O óleo é destinado ao uso familiar, seguidos de doação e venda, os preços variam entre R\$ 10,00 a R\$ 40,00. A atividade de extração do óleo é uma alternativa viável de renda aos extrativistas, possui grande potencial para promover o desenvolvimento local e possibilitar renda a esses trabalhadores.

Palavras-chave: Extrativismo. Amazônia. Produtos Não Madeireiros.

\section{ABSTRACT}

The present study aimed to describe the processes of traditional extraction of the oil of Carapa guianensis Aubl. (andiroba) in projects of Agroextrativistas settlements (PAEX) of the floodplains of the municipality of Igarapé-Miri, PA. The data were obtained through semi-structured questionnaires and with 14 people who work with andiroba on PAEX 4 - Solomon Mamangal, Mutirão, Jarembú And Buçu. The andiroba oil extraction is performed by 10 of the 14 respondents and consists of two amateurism: extraction in the inclined surface and in the adult. The oil extraction process involves three steps: collection and selection of seed preparation of the earth and the extraction of oil. The oil is intended for family use, followed by donation and sale, prices vary between $\mathrm{R} \$ 10.00$ to $\mathrm{R} \$ 40.00$. The activity of the oil extraction is a viable alternative to income to the extractive industries, has great potential for promoting local development and provide income to these workers.

Keywords: Extractivism. Amazon. Non-Timber Products. 
Introdução

A Carapa guianensis Aubl. (andiroba) é uma árvore que compõe a biodiversidade florísticas e biológica da Amazônia, pertence à família Meliaceae, ocorre em terra firme, mas é encontrada amplamente em regiões alagadas, estando concentrada em maiores proporções nos estados do Pará, Amapá, Amazonas e Roraima, em sociedade com árvores de virola/ucuuba (Virola surinamensis (Rol.) Warb.) (Myristicaceae), pracaxi (Pentaclethra macroloba (Wild.) O. Kuntze) (Leguminosae-Mimosoideae) entre outras (PRESCE, 2009).

A andirobeira é uma árvore do tipo perenifólia, possui de médio a grande porte, chegando a atingir entre 20 a 30 metros de altura. Sua madeira e o óleo extraído das sementes são dois dos produtos considerados mais importantes por terem diversas finalidades (FERRAZ, 2002; MENDONÇA e FERRAZ, 2007).

O óleo extraído das sementes de andiroba é um dos produtos florestais não madeireiros (PFNM's) mais conhecidos da Amazônia (GOMES, 2010). Os PFNM's são todos os materiais biológicos explorados da floresta que não se caracterizem como madeiras, sendo os frutos, óleos, resinas, extrativos, gomas, folhas, cogumelos, entre outros (BARROS e TRINDADE, 2017). O mercado para os PFNM's tem ganhado notoriedade devido ao aumento do consumo, o que valoriza a sua importância social e econômica, dessa maneira, é considerado uma alternativa bastante promissora para o desenvolvimento sustentável na Amazônia, em razão de proporcionar, ao mesmo tempo, produtos ao mercado com baixo impacto ambiental (GARCIA et al., 2018).

A andiroba possui grande potencial para o manejo e uso sustentável, através da atividade de coleta e extração de óleo. Essa atividade, pode promover o desenvolvimento local e renda aos extrativistas pela versatilidade tanto medicinal, atribuída ao óleo, como matéria-prima na fabricação de cosméticos. Além disso, a atividade de coleta de sementes e extração de óleo não é destrutiva, facilitando a conservação da biodiversidade, comparado a extração de madeira (MENDONÇA e FERRAZ, 2007; COSTA e MORAES, 2013).

Historicamente, o óleo de andiroba foi bastante utilizado na Amazônia. Entre os anos de 1854 a 1864, o óleo foi fartamente utilizado para a iluminação na cidade de Belém e no interior da Amazônia durante a 1ạ guerra mundial, quando houve a falta de querosene (FRANCO, 1998; MENEZES, 2005; HOMMA, 2014). De acordo com Leite (1997), houve forte comércio de sementes e óleo de andiroba na região do estuário amazônico, especificamente no século XIX, na cidade de Cametá, responsável por 2/3 da produção de óleo de andiroba produzido no estado do Pará.

Atualmente o óleo de andiroba tem apresentado interesse para a indústria e para pesquisas em diversas aplicações, devido as suas diversas características, como antialérgico, inseticida frente ao Aedes aegypti (Diptera: Culicidae), repelente, anti-inflamatório, acaricida e vermicida (CAVALCANTE et al., 2016). Santos e Pellicciotti (2016) enfatizam que o óleo de andiroba, possui grande potencial para promover a valorização das florestas devido a sua demanda no mercado para a fabricação de diversos produtos.

Grande parte do óleo produzido in natura é realizado de maneira artesanal por comunidades tradicionais, sendo consumida no mercado nacional. A manipulação dos recursos naturais para uso medicinal faz parte da identidade cultural dos povos e comunidades tradicionais da Amazônia (MENDONÇA e FERRAZ, 2007). Dessa maneira, manifestam suas percepções sobre os espaços produtivos a partir de suas relações com o ambiente e com a sua cultura em que os recursos vegetais, podem ser destacados em diversas etnocategorias de uso (DAVID e PASA, 2016).

Santos (2013) enfatiza que o uso medicinal do óleo de andiroba na região Amazônica, tem diversas finalidades, sendo provável que o conhecimento tradicional sobre sua também seja diverso, em função das interações de diferentes populações e ambientes. No entanto, existem poucas informações sobre a produção e comercialização de sementes e óleo de andiroba, não existe nenhuma entidade ou órgão público que fiscalize ou contabilize a produção seja artesanal ou industrial e a comercialização desse óleo. 
Por essa razão, tornam-se necessários estudos visando potencializar o reconhecimento, a disseminação e reprodução de dados consistentes sobre a produção e comercialização de sementes e óleo de andiroba, bem como os conhecimentos tradicionais no entorno dessa espécie, levando em consideração as estratégias adotadas pelas comunidades tradicionais para a perpetuação dessa espécie nos agroecossistemas.

Além disso, estudos dessa natureza podem estimular o fortalecimento do desenvolvimento local, a partir da valorização dessa atividade extrativista, como uma importante alternativa de renda para os extrativistas da região. Nesse sentido, este trabalho tem como objetivo descrever os processos de extração tradicional do óleo de Carapa guianensis Aubl. (andiroba) em Projetos de Assentamentos Agroextrativistas (PAEX) das várzeas do Município de Igarapé-Miri, PA.

Material e métodos

Área de estudo

Os dados foram coletados nas ilhas Mamangal, Mutirão, Buçu e Jarimbu. Essas ilhas são Projetos de Assentamentos Agroextrativistas (PAEX), localizados na região do Baixo Tocantins, entre as coordenadas $1^{\circ} 58^{\prime} 37^{\prime \prime}$ Sul, $48^{\circ} 57^{\prime} 34^{\prime \prime}$ Oeste, mesorregião do nordeste paraense, a $78 \mathrm{Km}$ da capital do estado do Pará, com área territorial de $1.996,790 \mathrm{~km}^{2}$ e índice populacional de 60.994 habitantes (IBGE, 2017).

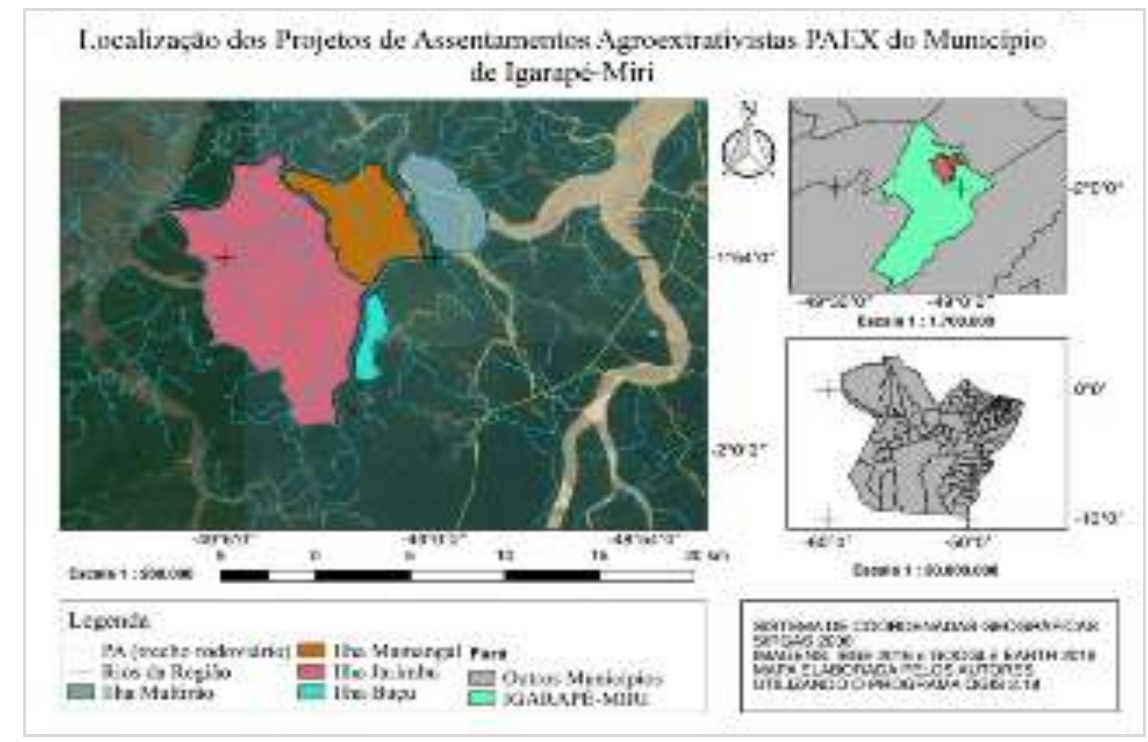

Figura 01. Mapa de localização do PAEX no município de Igarapé-Miri, PA.

Fonte: Elaborado pelo autor.

O clima nessa região é do tipo tropical, do tipo Am de acordo com a Köppen, temperatura média anual de $27^{\circ} \mathrm{C}$, umidade relativa de $80 \%$ e precipitação pluviométrica anual acima de $2.000 \mathrm{~mm}$ (TAVARES et al., 2016).

Nas várzeas, os solos são caracterizados por serem periodicamente inundados, possuem alto teor de nutrientes e são constantemente renovados (LIMA, 2015). A vegetação é formada de florestas secundárias, com espécies hidrófilas (água) e latifoliadas (de folhas largas), intercaladas com palmeiras locais (REIS e ALMEIDA, 2012). 
Processo metodológico

A pesquisa foi de cunho qualitativo que, de acordo com Silveira e Cordova (2009), é caracterizada por apresentar um aprofundamento na compreensão com aspectos da realidade que não podem ser quantificados, trabalham com o universo de significados, motivos, aspirações, crenças, valores e atitudes, o que corresponde a um espaço mais profundo das relações, dos processos em determinado fenômeno.

Para a coleta de dados, foram realizadas entrevistas com auxílio de questionários estruturados e semiestruturados, abordando os aspectos do processo de extração artesanal de óleo de andiroba, principais finalidades/usos e a comercialização.

Os entrevistados foram selecionados por amostragem não probabilística, através da metodologia snowball ou "Bola de Neve", apresentada por Vinuto (2014), em que os participantes iniciais de um estudo, indicam novos participantes ao pesquisador, que por sua vez indicam novos participantes e assim sucessivamente. O uso da técnica é encerrado quando os novos entrevistados passarem a repetir informações já adquiridas em entrevistas precedentes, ou até que seja alcançado o objetivo proposto.

As entrevistas foram gravadas em áudio, com prévia autorização e, após, foram transcritas na íntegra, e armazenadas em banco de dados eletrônico, visando a análise e interpretação. Para o consentimento na participação da pesquisa, foram disponibilizados aos respondentes o Termo de Consentimento Livre e Esclarecimento (TCLE), de acordo com as diretrizes estabelecidas pela resolução no 466/12, com todas as informações pertinentes à pesquisa, esclarecendo que o estudo é destinado apenas para fins acadêmicos, sem qualquer relação com finalidades econômica e comercial (BRASIL, 2012).

Os entrevistados foram classificados de acordo com a forma de trabalhar com a andiroba, sendo estes enquadrados nas seguintes tipologias: coletores que fazem apenas a coleta de sementes para a venda; coletores e extratores de óleo, que fazem paralelamente a coleta de sementes para a venda e extração de óleo; e extratores de óleo que fazem a coleta para extração de óleo.

Neste estudo, foram atribuídos códigos em forma de letras aos sujeitos da pesquisa para preservar a identidade dos informantes conforme Padilha et al. (2004).

A pesquisa foi cadastrada na plataforma Sistema de Autorização e Informação em Biodiversidade (Sisbio), com número de autorização 59154-1 e na plataforma do Sistema Nacional de Gestão do Patrimônio Genético e do Conhecimento Tradicional Associado (SisGen), com número de cadastro A98230C.

Os dados obtidos nos questionários foram tabulados e processados em planilhas eletrônicas elaboradas no Excel da Microsoft 2007 e os resultados, obtidos p foram interpretados mediante análise qualitativa.

\section{Resultados E Discussão}

\section{Coleta das sementes de andiroba}

Foram entrevistadas 14 pessoas que trabalham na atividade extrativista da andiroba nos PAEX de Igarapé-Miri, classificada de acordo com a forma de trabalho conforme a tabela 01.

Os coletores de sementes (G1) realizam apenas a venda de sementes de andiroba para uma empresa multinacional como uma oportunidade de renda, uma vez que, não possuem conhecimento e a prática de extração de óleo; os coletores e extratores (G2) otimizam o seu trabalho, visando o aumento da renda familiar praticando as duas atividades; e os extratores de óleo (G3) realizam exclusivamente essa atividade por dois motivos, primeiro por não precisar comprar o óleo para uso e, segundo, pela possibilidade de garantir rentabilidade maior e mais rápida do que a venda das sementes. 
Tabela 01. Tipologia dos trabalhadores de sementes de andiroba nos PAEX do município de Igarapé-Miri, PA.

\begin{tabular}{ccc}
\hline Entrevistados & Tipologia & Definição \\
\hline 4 & G1 - coletores de sementes & Pessoas que coletam sementes, apenas para a venda para uma \\
empresa multinacional.
\end{tabular}

De acordo com o relato dos entrevistados, o auge da queda das sementes de andiroba acontece entre janeiro a março, época mais chuvosas do ano, facilitando a disseminação das sementes pelos fluxos hídricos, já que todas as propriedades dos entrevistados possuem cursos d'água próximos às árvores. A coleta de sementes de andiroba ocorre quando a Euterpe oleracea Mart. (açaí), pertencente à família Arecaceae, principal produto de consumo e renda dos extrativistas entra na entressafra, entre o final do mês de dezembro até final do mês de junho.

Resultados semelhantes foram encontrados por Mellinger (2006) na Reserva de Desenvolvimento Sustentável Amanã, no Amazonas; Pena (2007), no sudeste do Pará; Pereira e Tonini (2012), na floresta natural localizada no sul de Roraima; e Santos (2013) na floresta de várzea no estado de Macapá.

As coletas das sementes são realizadas manualmente e acontecem, principalmente, nas unidades de produção familiar (UPF) dos entrevistados. As sementes são coletadas no chão, próximo à matriz, ou em pontos de acumulação deslocadas pela água, na maré baixa. Os extrativistas também aproveitam outras áreas do entorno das suas UPF para coletar sementes de andiroba, como as UPF de parentes, ao longo do rio e da Associação dos Minis e Pequenos Produtores Rurais de Igarapé-Miri - MUTIRÃO, que é uma organização social constituída por trabalhadores rurais para fortalecer o trabalho na região.

A coleta de sementes no rio é possível porque a semente de andiroba apresenta dispersão hidrocórica e, por essa razão, podem ser disseminadas através dos cursos de água pela sua leveza, que as fazem flutuar na água com facilidade. Além disso, essas sementes podem germinar enquanto flutuam, favorecendo a colonização de novas áreas, através do processo de regeneração natural, uma vez que possuem alta capacidade de germinação (PEREIRA e TONINI, 2012; ISLA et al., 2018).

Para o transporte das sementes são utilizadas rasas ou sacas de polietilenos. Os critérios adotados para a seleção das sementes são: sementes novas, sem germinação e sem furos causada pela lagarta Hypsipyla grandella (Zeller) (Lepidoptera: Pyralidae), conhecida como a broca-de-andiroba.

As sementes germinadas são deixadas no local para que possam se desenvolver e formar nova planta dentro das UPF. As sementes furadas pela Hypsipyla grandella apenas são coletadas por uma extratora de óleo que aproveita esse tipo de semente para produzir o óleo que vai para olaria, o restante dos extrativistas não coletam, pois são sementes danificadas, inviabilizada para a venda e extração de óleo para fins medicinais.

A ocorrência da broca-de-andiroba também foi verificada por Calle (2012), na reserva extrativista do rio Jataí no Amazonas; Silva et al. (2015), na floresta de várzea estuarina na Amazônia; Santos (2013), em floresta de várzea periurbana, no estado do Amapá; e Jesus-Barros et al. (2015), em floresta de várzea, em Macapá.

\section{Preparo da massa de andiroba}

As sementes de andiroba são cozidas em latas ou em panelas grandes do tipo caldeirão em fogo a lenha, conforme a especificidade de cada extrator, como descritos pelos entrevistados:

A gente seleciona as sementes boas, sem grelo e sem furo, cozinha três horas em uma lata, e de vez em quando amassa uma para saber se a casca já está mole. Tira da água e deixa descansar um mês na cama abafada com folha de 
aningueira até secar toda água do cozimento e depois desse tempo eu ponho no tipiti e o óleo cai na bacia (Extrator A).

Pra fazer o óleo tem que ajuntar as sementes novas e sem furos, lavar e botar para ferver dentro de uma vasilha, uma panela grande ou uma lata e ferve, ferve, ferve em uma hora de tempo. Depois que termina de ferver coloca dentro de um paneiro, aí pega umas folhas e cobre tudinho e deixa lá por um mês. Depois de um mês tira a massa das castanhas para escorrer o óleo, e escorre o dia todo na sombra e depois eu guardo o azeite (Extrator B).

A gente coleta todas as sementes, aqui a gente faz uma seleção das boas, as sementes boas a gente aperta e elas não sedem e as brocadas a gente aperta e ela já sedem porque estão ocas e se botar essas sementes dá um azeite velho e ensebado, mais a gente aproveita porque esse vai para olaria e o óleo limpo tem que ser apenas das sementes boas. Aí a gente cozinha, cozinha no tacho, depois que a água com as sementes ferve, com 15 a 20 minutos abaixa o taxo e joga numa lata por 30 dias e gente quebra a casca tira a massa. A gente deixa a massa descansar três dias e amassa bem e depois já pode botar para escorrer o azeite no tipiti. Quando não sair mais óleo a gente tira e amassa e amassa e leva para o sol para esquentar para terminar de sair o óleo (Extrator C).

A gente coleta as sementes novas, sem furos e cozinha até o ponto de ficar bom, a gente abaixa a fogo. Ai a gente escorre aquela água no paneiro, daí a gente deixa de 25 a 30 dias descansando. Depois a gente pega e tira de lá e quebra as sementes, pega o pão, empalha com a folha de aninga e deixa passar por três dias e depois põe na tabua, vou fazendo a bolinha e colocando, fazendo a bolinha e colocando, aí tampo todinho com a folha, no outro dia eu vou ver e já começou a cair o azeite na vasilha em baixo feito na sombra. São oito dias para sair todo o azeite da massa (Extrator D).

Eu coleto as sementes boas, sem grelo e sem furo e cozinho em latas eu coleto e cozinho por muito tempo. Deixo um mês descansando na rasa enrolada com folhas de bananeira, depois de 15 dias a gente revira as sementes. Quando completava um mês começa a tirar, quebrando as sementes e tira com colher de pau a massa e botava no tipiti na sombra e tirava o óleo (Extrator E).

Coleta a semente, a gente seleciona, tira as que possa tá com a broca e vai pro cozimento, a gente cozinha 20 minutos de duração de fervura. Depois da fervura espalha em lugar arejado para que ela possa ficar 30 dias, depois desses dias vai quebrar a castanha e vai tirar a massa ai vai armazenado em peneiros forrados com folhas de aningueira por três dias esquentando e depois desses dias a gente arruma na tabua para escorrer o azeite que dura entre 8 a 10 dias. Só não pode levar pro sol, se não pega um outro cheiro, forte, então a gente pode de baixo da casa e de preferência que não pegue sol (Extrator F).

Ajunta as castanhas boas sem está brocada, vem do mato, põe numa lata, cozinha e aperta o ladinho mais fino dela e aperta lá, se tiver mole ela já tá boa se não a gente deixa mais. Eu nunca contei os minutos eu me baseio na semente porque quem cozinha mais é meu marido e quando ele não tá eu que cozinho, mais é pouco. Ai quando a gente tira de cozir a gente joga dentro de uma raza e cobre com folha de açaí ou cacau e deixa lá por 30 dias, ai depois disso a gente pega e tira o azeite (Extrator $\mathrm{G}$ ).

Eu coleto, faço o fogo e cozinha até ficar mole a casca, tira e deixa esfriar e espalha a semente. Com 15 dias vira as sementes e com 30 dias quebra elas e espreme no tipiti (Extrator $\mathrm{H}$ ).

Vou buscar a semente no mato e vamos cozer, cozinha mais ou menos uma hora e agasalha ele por 20 dias pra poder tirar, eu vou colocando na vasilha 
para amassar a primeira vez e coloco um pouco de sal e vou amassando e pondo numa telha e amassa duas a três vezes por dia até escorrer todo o azeite (Extrator I).

Eu seleciono as sementes sem furos e cozinho, depois deixo a massa descansado por 30 dias e tiro das castanhas e Passa dois a três minutos batendo cinco a seis vezes no dia, quanto mais bate a massa, mais da líquido e se não bater seca a massa (Extrator J).

A partir das falas dos extratores, constatou-se que, na coleta e seleção das sementes de andiroba, os critérios de escolha e seleção não diferiram entre os extratores de óleo, só foram verificadas divergências no modo de preparo das sementes para extração de óleo, relacionas ao tempo de cozimento das sementes, tempo de repouso das sementes para a fermentação, tipo de folhas que são usadas para cobrir (abafar) as sementes durante a fermentação e no cuidado do preparo relacionado às superstições.

O tempo de cozimento das sementes varia entre os informantes, entre 15 minutos a 3 horas. No entanto, alguns extratores de óleo que não se embasam no tempo e sim no amolecimento das sementes, para tanto, vão amassando com frequência até a casca da semente estar completamente amolecida.

Resultados semelhantes foram encontrado por Santos (2013) ao estudar o processo de extração do óleo de andiroba em floresta de várzea no estado de Macapá, encontrou que uma parcela dos extratores sabia o ponto de cozimento das sementes quando a casa quebrava com facilidade e a outra parcela preferia controlar o tempo, que durava de 15 minutos a 7 horas.

Em relação ao tempo de repouso das sementes após o cozimento para a fermentação, a variação é de 20 a 30 dias. De acordo com os extratores de óleo, essa diferença de tempo ocorre pela quantidade de sementes que foram cozinhadas, quanto mais sementes, maior é o tempo de descanso. Mendonça e Ferraz (2007) e Barbosa (2015) observaram que no município de Manacapuru, no estado do Amazonas, e na floresta nacional do Amapá, o tempo que as sementes cozidas ficam de repouso antes de começar o processo de amassamento ou sovagem da massa varia de 8 dias até 45 dias e 7 a 20 dias, respectivamente.

Sobre os materiais usados para cobrir e abafar as sementes cozidas no processo de fermentação, foi identificado o uso dos próprios recursos vegetais existentes no ecossistema de várzea, como folha de Montrichardia linifera (Arruda) Schott (aningueira) (Araceae), Musa spp (bananeira) (Musaceae), Theobroma cacao L. cacaueiro (cacaueiro) (Malvaceae) e açaizeiro, hábito também verificado por Silva (2009), na ilha de Juba no município de Cametá no Pará e Santos (2013), em floresta de várzea de Macapá.

\section{Extração de óleo de andiroba}

A extração do óleo de andiroba nas várzeas mirense é realizada por dois métodos artesanais: o processo de extração de óleo feito em superfície inclinada citado por cinco entrevistados e o processo de extração no tipiti citado pelos outros cinco extratores.

O método de extração em superfície inclinada consiste em depositar a massa ou pão-de-andiroba em uma estrutura inclinada para liberar gradativamente o óleo por gotejamento (FERRAZ et al., 2002). Os materiais adotados pelos extratores nas várzeas de Igarapé-Miri para montar essas superfícies inclinadas foram: tábua, folhas de alumínio e telha de cerâmica.

Resultados semelhantes foram encontrados por Mendonça e Ferraz (2007) nas várzeas do estado do Amazonas, que encontraram diversidade de materiais usados para realização da extração em superfície inclinada, como folhas de zinco, cocho feito de pedaço de metal, canoa velha ou pedaço de madeira.

É importante destacar que todos os extratores de óleo, que realizam o método de obtenção de óleo por superfície inclinada, independente do material usado, enfatizaram que esse procedimento se 
denomina extração na tábua. Dessa maneira, pode-se constatar que esse método foi passado de geração em geração e ainda é preservado, no entanto, com algumas adaptações no material usado no processo.

Outro aspecto relevante são as distintas formas de como a massa é disposta sobre as estruturas inclinadas. Os extratores de óleo moldam o material da forma como consideram mais eficiente para o escorrimento do óleo, que é arrumar a massa das amêndoas em formato de bolas ou aglomerar o material retirado das sementes em uma única estrutura, chamada de "pão-de-andiroba". Esses resultados condizem com o que Santos (2013) encontrou ao verificar a extração artesanal do óleo de andiroba em uma área de proteção ambiental em floresta de várzea periurbana, no estado de Macapá, onde encontrou as mesmas maneiras de dar forma à massa.

Com relação à extração no tipiti, prensa típica da Amazônia, era muito utilizada para espremer a massa de mandioca para a produção de farinha pelos indígenas, na língua tupi significa "cesto para espremer água" (SOENTGENA e HILBERTB, 2016). Essa ferramenta de trabalho é feita a partir a do caule de Mauritia flexuosa L. (Arecaceae), conhecido popularmente como buriti/miriti, que são entrelaçados de forma cilíndrica para receber a massa de andiroba cozida para a separação do óleo.

O método de extração de óleo é decorrente dos conhecimentos tradicionais e técnicas repassados principalmente pela mãe, como relatado por nove extratores e um aprendeu com uma prima. Dessa maneira, é perceptível que os saberes são passados através da oralidade, observação e prática, e representam a valorização dos traços culturais familiares. As transmissões de saberes e a sua valorização contribuem para a retomada de tradições milenares (PELEGRINI e FUNARI, 2017).

Observou-se que existem várias crenças e superstições enraizadas no cotidiano dos extratores de óleo, que permeiam a atividade de extração de óleo de andiroba. Entre elas, o mal olhado das mulheres menstruadas e grávidas, mencionada por quatro extratores, em que um destacou: "mulher menstruada e grávida não pode tirar o azeite, porque o azeite não escorre e fica ensebado, principalmente mulher grávida, porque a gente observou ao longo do tempo". Esses resultados corroboram com os encontrados por Mendonça e Ferraz (2007); Furtado (2012); Santos (2013) e Santos et al (2014) sobre crenças no processo tradicional de extração de óleo de andiroba.

Outras superstições também foram relatadas, como "Não botar a andiroba para cozinhar com a água em cima da terra, água lançante ela dá muita água e custa a secar", outro ressaltou que "não pode deixar ninguém de fora olhar para azeite não desandar" $e$ "se morrer um da nossa família a gente não podia coletar enquanto não fizesse oito dias, porque se não o azeite não escorre".

Vale ressaltar que existem também os que não acreditam em crenças e superstições a respeito do processo de extração do óleo de andiroba" não possuo superstição, não acredito" e "aqui em casa a gente não acredita em superstições". Isso reflete que, dentro de um determinado território, existem uma diversidade cultural, com diversos elementos simbólicos que se diferenciam e constituem a identidade cultural de um determinado local, possibilitando a vivência de várias experiências.

As crenças dos povos amazônicos são transmitidas através da oralidade, em que o natural e o sobrenatural caminham juntos na construção das suas histórias de vida (SILVA, 2009). Para Toledo e Barrera-Basols (2009), as sociedades tradicionais albergam um repertório de conhecimento que, geralmente, é local, coletivo, diacrônico, sincrético, dinâmico e holístico, no qual esses sistemas cognitivos sobre os recursos naturais circundantes, são transmitidos de geração a geração através dos seus sistemas de crenças (cosmos), conjunto de conhecimentos (corpus) e práticas produtivas (práxis).

Ao serem questionados sobre a predileção pelo tipo de extração, os extratores afirmaram que preferem a extração à sombra, pois a qualidade do óleo é melhor, e apresenta um aspecto mais limpo, mesmo que seja um processo mais demorado se comparado ao retirado ao sol, onde o óleo tende a se solidificar e, por isso lhe atribuem uma qualidade inferior. Um extrator relatou: "na sombra sai um azeite muito bonito e forte, se tirar no sol com o tempo ele fica ensebado, não presta"., outro comentou: "é feito na sombra o meu óleo, no sol ele não sai normal, quando a gente acaba de coletar pra pôr na garrafa ele fica duro, na sombra sem ajuda do sol o azeite sai líquido verde e lindo". 
Apenas a extratora $\mathrm{C}$ realiza a combinação dos métodos sombra e sol como relatado: "tiro óleo tanto na sombra quanto no sol, primeiro para escorrer o azeite no tipiti que é aqui na sombra, quando não sair mais óleo eu amasso e levo para o sol para sair todo o resto do óleo da massa". Esse relato mostra que essa extratora realiza o aproveitamento total do óleo da massa/pão de andiroba. No entanto, em virtude da pureza do óleo extraído no sol ser menor e menos valorizado por se solidificar mais rápido, esse óleo é vendido para as olarias para fabricação de velas.

A escolha do método de extração à sombra reflete na qualidade do óleo que, segundo os extratores, há diferentes tipos de óleo de andiroba, e essa qualidade está atribuída à cor do azeite após a extração. Foram identificadas duas cores: um verde e outro amarelo com algumas variações de tons (Figura 02).

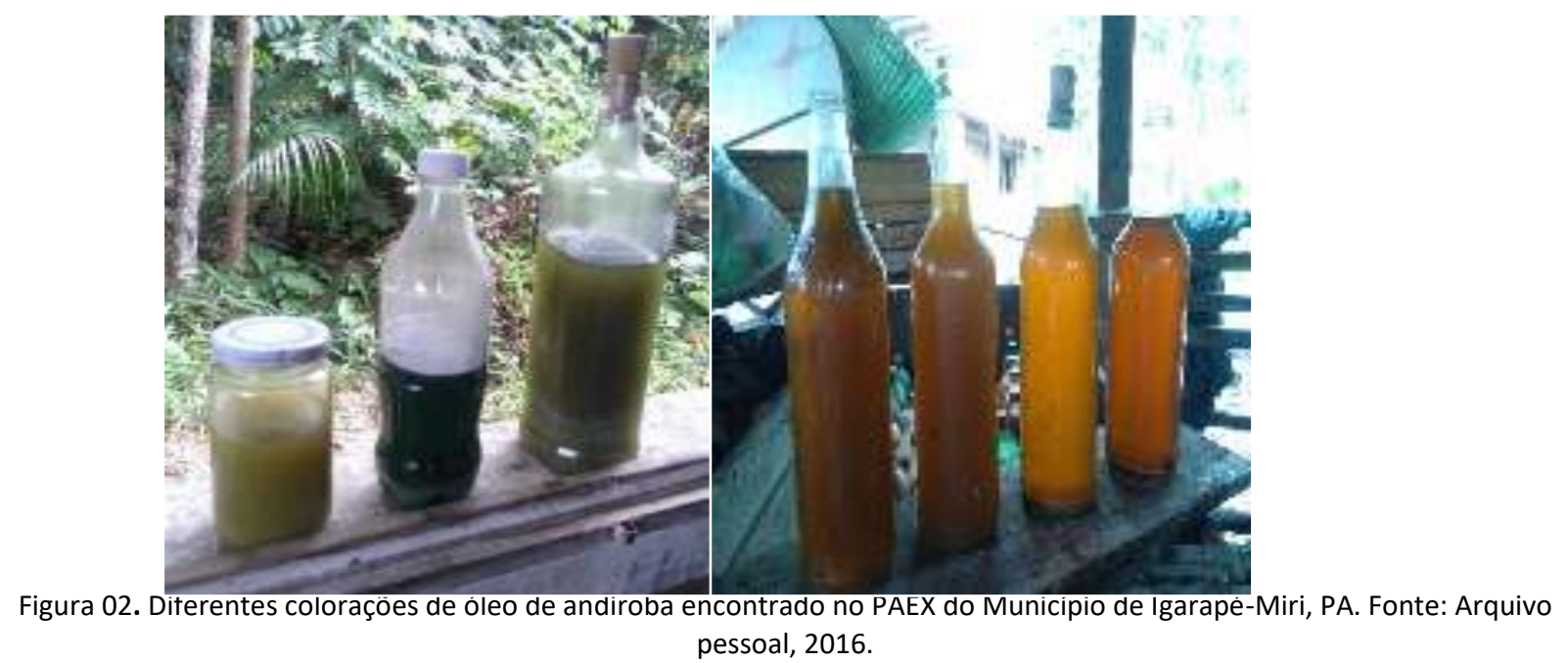

Segundo os entrevistados, a cor verde é atribuída ao primeiro óleo que escorre da massa de andiroba. De acordo com o tempo que a massa passa escorrendo, a coloração tende a ficar em vários tons amarelados, até chegar ao ponto do óleo se solidificar, ficando esbranquiçado. Resultados semelhantes foram encontrados por Santos (2013), em floresta de várzea no Amapá.

\section{Resíduos do processo extrativo}

O processo de extração deixa dois resíduos: as cascas das sementes e a massa ressecada após o encerramento da extração do óleo. A queima consiste no principal destino dado aos resíduos, citado por oito extratores, seguidos da produção de sabão, relatada por um entrevistado e adubação, mencionado por um entrevistado.

As cascas e a massa seca são queimadas tanto nas frentes das casas quanto nos arredores, como efeito repelente para afastar insetos hematófagos que causam incômodos e problemas cutâneos, como carapanã (Culex quinquefasciatus Say, 1823) (Culicidae) e maruim (Culicoides sonorensis Wirth \& Jones) (Ceratopogonidae). Esses resultados condizem com o encontrado por Mendonça e Ferraz (2007) e Silva (2009).

Apenas um entrevistado enfatizou que além de queimar as cascas para espantar insetos, utiliza como fogueira para comemorar um dia santo, como descrito: "lá na frente a gente fez uma luminária de são João, onde eu coloquei a casca da andiroba, e fazer fumaça para espantar insetos"

\section{Uso, armazenamento e comercialização}

O óleo de andiroba é usado por gerações, sendo amplamente utilizado por todos os entrevistados. Os principais sintomas tratados e citados com maiores frequências de uso foram: machucados que englobam as feridas, baques, lesões, picada de inseto, relatado por todos os 
entrevistados, seguidos de inflamações citado por 12 entrevistados, principalmente na garganta, prurido (coceiras) mencionado por dez, repelente por três, gripe e tosse por dois, e azia por um.

Ao serem questionados sobre a preferência do tratamento dos sintomas apresentados com essa oleaginosa, quando comparado aos remédios farmacêuticos, todos os entrevistados afirmaram preferir se tratar com óleo de andiroba, por ser um recurso de fácil acesso e totalmente natural, capaz de curar qualquer enfermidade. Um dos entrevistados declarou: "usamos o óleo porque é natural, a gente até compra outros remédios aqui em casa, as vezes nós compra remédio de farmácia porque não tem aonde plantar"; outro relatou: "nós sempre usamos e vamos usar porque é natural, e é um dos melhores remédios que se tem, esse de farmácia, não presta".

Dessa maneira, pode-se perceber que o óleo de andiroba faz parte da medicina local dos ribeirinhos, a versatilidade desse óleo contribui para a difusão do conhecimento acerca das distintas formas de usos e aplicações no tratamento medicinal além de garantirem a manutenção da saúde da população local.

Resultados semelhantes foram encontrados por Calle et al. (2014), ao estudarem comunidades tradicionais na Resex do Rio jataí. Os autores detectaram que a população tem uma forte relação com o poder medicinal do óleo de andiroba, e esta relação estava vinculada à frequência e à diversidade de uso. Badke et.al. (2012) destacaram que, nas últimas décadas, mesmo com o desenvolvimento dos fármacos sintéticos, o uso de plantas medicinais permanece como forma alternativa de tratamento em várias partes do mundo, e essa forma de resistência tem contribuído com a valorização do emprego de preparações à base de plantas para fins terapêuticos.

Santana et al. (2018) destaca que o uso de plantas com caráter medicinal para prevenir e curar doenças, além de ter um baixo custo, diminuir o risco de toxicidade em decorrência do uso de medicamentos industrializados, proporcionando a continuação do uso por gerações pelas populações usuárias que acreditam em todo um contexto histórico criado desde seus antepassados até os dias atuais.

O armazenamento do óleo de andiroba é feito, principalmente, em garrafas de vidro, citado por seis entrevistados, porque acreditam que nessa embalagem o azeite não fica rançoso e assim, pode durar mais de cinco anos guardados, quatro armazenam tanto em garrafas PETs reaproveitadas de água ou refrigerante quanto nas de vidros.

Dos que armazenam em garrafas plásticas, um citou que condiciona apenas o óleo que vai para olaria nessa embalagem e o restante relatou que, apesar de notar alteração da coloração e a mudança na consistência de líquida para pastosa (gordura), usam esse tipo de embalagem, por serem de fácil acesso.

De acordo com Monteiro (2017), o óleo de andiroba solidifica em temperaturas abaixo de 25으 C, tornando-se uma gordura esbranquiçada. Para Brasil et al. (2011) as qualidades dos óleos vegetais dependem de vários fatores, como tipo de processamento, forma de armazenagem, exposição à luz e ao oxigênio do ar, calor e umidade. Todos provocam reações de degradação das propriedades do óleo de andiroba, limitando a sua conservação (SIMÕES et al., 2004).

A maior parte do óleo produzido pelos extratores de óleo das várzeas miriense é destinado ao uso familiar, seguidos da venda direta ao consumidor, que na maioria são os próprios moradores da região, doação (parentes e amigos), venda para atravessador e olarias.

Sobre o valor do litro de óleo, observou-se instabilidade de preço, variando de $R \$ 10,00$ a $R \$$ 40,00. Barbosa (2015) e Soares et al (2017) também encontraram variação de preços do litro do óleo artesanal de andiroba na floresta nacional do Amapá e no município de Salvaterra no estado do Pará, em que o preço pago no litro variava de $R \$ 25,00$ a $R \$ 40,00$.

No que diz respeito à percepção dos extratores sobre o óleo que é extraído por eles na comunidade, em comparação ao óleo vendido em outros locais (cidade de Igarapé-Miri e redondezas), foi mencionado que há uma grande diferença. Um dos entrevistados destacou: "o óleo de fora é adulterado, vem gorado e ensebado, o nosso é puro, se eu não tirar o óleo eu compro de alguém na comunidade que tira, pois aqui nós sabe que é confiável". Essa fala reflete a forte relação dos laços 
sociais entre os ribeirinhos, favorecendo a consolidação da vida comunitária a valorização do óleo na região.

Não foi relatada nenhuma dificuldade relacionada ao comércio do óleo de andiroba pelos extratores, pois na região tem muita procura para fins medicinais, principalmente por parte dos moradores que não realizam extração de óleo. Dessa maneira, pode-se perceber que a produção de óleo de andiroba nas várzeas tem contribuído significativamente para a continuação das práticas tradicionais locais de extração de óleo, aliando geração de renda e conservação socioambiental.

\section{Conclusão}

A atividade de extração de óleo de andiroba nas várzeas miriense tem grande importância no contexto econômico, social e cultural das populações ribeirinhas, principalmente por estar ligada ao uso medicinal, atribuído do óleo, com potencial para promover o desenvolvimento local e geração de renda aos extrativistas. O dinamismo do conhecimento tradicional é visível na maneira de se extrair artesanalmente o óleo de andiroba no PAEX, que vai desde as formas de extração, usando materiais diferente, tipos de extração, os procedimentos do processo de beneficiamento do óleo, das crenças estabelecidas para o processamento e pós-processamento com o destino dos resíduos.

Nota-se que, mesmo com essa diversidade de conhecimentos, os extratores mantêm a essência do processo extrativo em garantir um óleo de excelente qualidade, que é bastante apreciado e valorizado pelos próprios ribeirinhos da região. Essa valorização, permite não só a geração de renda, como também o fortalecimento da atividade, a conservação da andirobeira dentro das UPF, a valorização dos saberes, das práticas e valores culturais acerca dos processos extrativos do óleo artesanal, permitindo a consolidação da identidade local.

Os resultados gerados nessa pesquisa podem ser úteis na elaboração de planos e estratégias de comercialização da produção agroextrativista da andiroba nas várzeas mirense. No entanto, é imprescindível que mais pesquisas dessa natureza sejam realizadas, para que possa fortalecer a abordagem dos produtos não madeireiros na região e para obtenção de dados confiáveis para propor ações que estabeleçam melhores condições de manejo, uso e conservação da espécie.

\section{Referências}

BADKE, M. R.; et al. Saberes e práticas populares de cuidado em saúde com o uso de plantas medicinais. Revista Florianópolis, v.21, n. 2, p. $363-70,2012$.

BARBOSA, R. C. Estudo do potencial da produção de óleo de andiroba (Carapa guianensis Aubl.) na floresta nacional do Amapá: aspectos ecológico, econômico e social. Macapá, AP: 2015. 59p. Trabalho de Conclusão de Curso (Bacharelado em Ciências Ambientais) - Universidade Federal do Amapá. 2015.

BARROS, B. T.; TRINDADE, P. C. Análise da produção de Produtos Florestais Não Madeireiros no Brasil e no Pará entre 1990-2015. 2017. Revista Observatorio de la Economía Latinoamericana. Disponível em: http://www.eumed.net/cursecon/ecolat/br/17/producao-produtos-florestais.html. Acesso em: 12 de mar 2019.

BRASIL, R. V.; et al. Caracterização física e química do óleo de pequi exposto a diferentes condições de armazenamento. In: REUNIÃO ANUAL DA SOCIEDADE BRASILEIRA PARA O PROGRESSO DA CIÊNCIA, 63., 2011. Maceió. $\quad$ Anais... Maceió: $2011 . \quad$ SBPC, Disponível em: http://www.sbpcnet.org.br/livro/63ra/conpeex/pibic/trabalhos/renata_v.pdf. Acesso em: 15 set. 2018.

BRASIL. Resolução n. 466, de 12 de dezembro de 2012. Aprova diretrizes e normas regulamentadoras de pesquisas envolvendo seres humanos. Diário Oficial da União, Brasília, v.24, 15p, 2012.

CALLE, D. A. C. Manejo, conservação e mudanças comunitárias associadas ao uso de andiroba (Carapa spp.) na Reserva Extrativista do Rio Jutaí-Amazonas. Manaus, AM: 2012. 92p. Dissertação (Mestrado em ciências florestais tropicais) - Instituto Nacional de Pesquisa na Amazônia. Amazonas, 2012.

CALLE, D. A. C; et al. Práticas de uso e manejo tradicional de Carapa spp. (andiroba) na Reserva Extrativista do Rio Jutaí, Amazonas, Brasil. Revista Ciências Humanas, v. 1, n. 1, p. 519 - 540, 2014.

CAVALCANTE, G. H. R.; et al. Estudo viscosimétrico de polióis a base do óleo de andiroba (Carapa guianensis Aubl.). Revista Virtual de Química, v. 8, n. 3, p. 926-944, 2016. 
COSTA, J. R.; MORAES, R. R. Carapa guianensis Aubl. (andirobeira) em Sistemas Agroflorestais. EMBRAPA Amazônia Oriental, 2013. 21 p.

DAVID, M.; PASA, M. Ribeirinhos e recursos vegetais: a etnobotânica em Bonsucesso, Várzea Grande, Mato Grosso. FLOVET - Boletim do grupo de pesquisa da flora, vegetação e etnobotânica, v. 1, n. 8, p. 35 - 49. 2016.

FERRAZ, I. D. Andiroba Carapa guianensis Aubl. 2003. Disponível em: https://www.inpa.gov.br/sementes/iT/1_Andiroba.pdf. Acessado em: 27 dez. 2018.

FERRAZ, I. D.; et al. sementes e plântulas de andiroba (carapa guianensis Aubl. e carapa procera Dc): aspectos botânicos, ecológicos e tecnológicos. ACTA AMAZONICA, v. 32, n. 4, p. 647- 661, 2002.

FRANCO, E. O Tapajós que eu ví (Memórias). Santarém, Coordenadoria Municipal de Cultura, 1998. 176p.

FURTADO, D. C. Entre o extrativismo e a catação: utilização das sementes de andiroba (Carapa Guianensis Aublet.) no Município de Marapanim (Pará, Brasil). 2012. 118 P. Dissertação (mestrado em Agriculturas Familiares e Desenvolvimento Sustentável) - Universidade Federal do Pará. Belém, 2012.

GARCIA, W. S.; et al. Demanda de produtos florestais não madeireiros: o caso do açaí e da castanha-do-pará. Revista em Agronegócio e Meio Ambiente, v. 11, n. 4, p. 1039-1059, 2018.

GOMES, H. S. R. Estrutura populacional e produção de andiroba em terra firme e várzea no sul do Amapá 81 p. 2010. Dissertação (Mestrado em Biodiversidade tropical) - Universidade Federal do Amapá, Macapá, 2010.

HOMMA, A. K. O. Extrativismo vegetal na Amazônia: história, ecologia, economia e domesticação. Brasília, DF. Embrapa, 2014. 468 p.

INSTITUTO BRASILEIRO DE GEOGRAFIA E ESTATÍSTICA - IBGE. Censo do município de igarapé-mirim-PA. 2017. Disponível em: https://cidades.ibge.gov.br/ brasil/pa/igarape-miri/panorama. Acesso em: 02 de jun. de 2018.

ISLA, C. D. S.; et al. Estrutura e distribuição espacial de uma população de Carapa guianensis Alblet em floresta de várzea do Estuário Amazônico. In: CONGRESSO FLORESTAL LATINO-AMERICANO, 7., Vitória, 2018. Anais.... Espirito Santo, v.3, 2018.

JESUS-BARROS, C. R.; et al. Registro da ocorrência de Hypsipyla ferrealis e Hypsipyla grandella (Lepidoptera: Pyralidae) em frutos de andirobeiras (Carapa guianensis, Meliaceae) em Macapá-AP, Brasil. Ciência Florestal, v. 25, n. 3, p. 765-769, 2015.

LEITE, A. M. C. Ecologia de Carapa guianensis Aublet. (Meliaceae) "andiroba”, 1997. 181p Tese (Doutorado em Biologia Ambiental) - Universidade federal do Pará/Museu Paraense Emilio Goeldi, Belém. 1997.

LIMA, R. S. Na safra e na entressafra do açaí: usos do território e modo de vida da população ribeirinha do baixo Rio Meruú (Igarapé - Miri/PA). 2015. 138 p. Dissertação (Mestrado em Geografia) - Instituto de Filosofia e Ciências Humanas, Universidade Federal do Pará, Belém, 2015.

MELLINGER, L. L. Aspectos da regeneração natural e produção de sementes de Carapa guianensis Aubl. (andiroba) na Reserva de Desenvolvimento Sustentável Amanã (AM). 2006. 81 f. Dissertação (Mestrado em Ciências Biológicas) - Instituto Nacional de Pesquisas Amazônicas, Universidade Federal do Amazonas, Manaus.2006

MENDONÇA, A. P.; FERRAZ, I. D. K. Óleo de andiroba: processo tradicional da extração, uso e aspectos sociais no estado do Amazonas, Brasil. Acta Amazônica, vol. 3, p. 353 - 364, 2007.

MENEZES, A. J. E. A. O histórico do sistema extrativo e a extração de óleo de andiroba cultivado no município de Tomé-Açu, estado do Pará. $2005 . \quad$ Disponível em: https://www.alice.cnptia.embrapa.br/alice/bitstream/doc/576188/1/142.pdf. Acesso em: 15 nov. 2018.

MONTEIRO, M. V. M. Avaliar a atividade antimicrobiana de óleos essenciais Citronela (Cymbopogon winterianus) e Andiroba (Carapa guianensis Aubl) em cepas clínicas de Staphylococcus aureus e Escherichia coli. 2017. Disponivel em: https://ri.ufs.br/bitstream/riufs/7450/2/MICHELE_VIT\%C3\%93RIA_DE_MELO_MONTEIRO.pdf. Acessado em: 11 out 2018.

PADILHA, M. I. C.; et al. A Responsabilidade do pesquisador ou sobre o que dizemos acerca da ética em pesquisa. Texto \& Contexto Enfermagem, v. 14, n. 1, p. 96-105, 2004.

PELEGRINI, S.; FUNARI, P. O que é patrimônio cultural imaterial. 1. ed. São Paulo: Brasiliense, 2017. 79 p.

PENA, J. W. P. Frutificação, produção e predação de sementes de Carapa guianensis AUBL. (Meliaceae) na Amazônia Oriental Brasileira. 2007. 60 f. Dissertação (Mestrado em Ciências Florestais) - Universidade Federal Rural da Amazônia, Belém, 2007.

PEREIRA, M. R. N.; TONINI, H. Fenologia da andiroba (Carapa guianensis, Aubl., Meliaceae) no sul do estado de Roraima. Ciência Florestal, v. 22, n. 1, p. 47-58, 2012.

PRESCE, C. Oleaginosas da Amazônia. 2 ed. Belém, Museu Paraense Emilio Goeldi, 2009.

REIS, A. A. R.; ALMEIDA, O. T. Desenvolvimento sustentável e estratégias de uso dos recursos naturais em área de várzea no Baixo Tocantins, Amazônia. In: Desenvolvimento \& Sustentabilidade. Oriana Trindade de Almeida, Sílvio Lima Figueiredo, Saint-Clair Cordeiro da Trindade Jr. (Organizadores) - Belém: NAEA, 2012. p.161-176.

SANTANA, M. D. O. et al. O poder das plantas medicinais: uma análise histórica e contemporânea sobre a fitoterapia na visão de idosas. Multidebates, v. 2, n. 2, p. 10-27, 2018. 
SANTOS, M. Conhecimento Ecológico Local sobre as Andirobeiras e a Extração Artesanal do Óleo de Andiroba em Uma Área de Proteção Ambiental, Floresta de Várzea Periurbana. Macapá. 2013. 110p. Dissertação (Biodiversidade Tropical) - Universidade Federal do Amapá.

SANTOS, M. N.; et al. Saberes tradicionais em uma unidade de conservação localizada em ambiente periurbano de várzea: etnobiologia da andirobeira (Carapa guianensis Aublet). Boletim do Museu Paraense Emílio Goeldi. Ciências Humanas, v. 1, n. 1, p. 93-108, 2014.

SANTOS, R. S.; PELLICCIOTTI, A. S. Ocorrência de Hypsipyla ferrealis Hampson (lepidoptera: pyralidae) em andiroba no estado do acre. Ciência Florestal, v. 26, n. 3, p. 995-998, 2016.

SILVA, A. M. F. Saberes cotidianos e azeite de Andiroba: A presença da mulher extrativista, no contexto histórico das práticas socioculturais dos sujeitos da Ilha de Juba, Cametá-Pa. 2009. 370 p. Dissertação (Mestrado em História Social na Amazônia) - Universidade Federal do Pará, Belém, 2009.

SILVA, K. P.; et al. Produção e predação de sementes de andiroba em floresta de várzea estuarina na Amazônia. In: Embrapa Amapá-Artigo em anais de congresso. In: encontro latino americano de universidades sustentáveis, 2., 2015, porto alegre. Desafios do desenvolvimento sustentável para universidades latino americanas após a década da educação e os objetivos do milênio. Porto Alegre: Escola de Administração. UFRGS, 2015.

SILVEIRA, D.T; CÓRDOVA, F. P. Unidade 2-a pesquisa científica. Métodos de pesquisa. Porto Alegre: UFRGS, p. 3142, 2009.

SIMÕES, C. M. O. et al. Farmacognosia: da planta ao medicamento., ed. 5. Porto Alegre: UFSC, 2004

SOARES, I. D. S.; OTOBO, A. O.; RIBEIRO, C. F. A.; ESPIRITO SANTO, K. R.A. Caracterização socioeconômica e de aspectos produtivos do extrativismo de sementes oleaginosas amazônicas na mesorregião do Marajó-Município de Salvaterra, Pará, Brasil. Revista Observatorio de la Economía Latinoamericana, v2, p. 1-23, 2017.

SOENTGENA, J.; HILBERT, K. A Química Dos Povos Indígenas Da América Do Sul. Quim. Nova, Vol. 39, N. 9, 11411150, 2016

TAVARES, A. A. S.; et al. Estatística municipal de Igarapé-Miri. Fundação Amazônia de Amparo a Estudos e Pesquisas - FAPESPA. 2016. Disponível em: http://www.parasustentavel.pa.gov.br/wpcontent/uploads/2017/04/Igarape\%CC\%81-Miri.pdf. Acesso em: 15 nov 2018.

TOLEDO, V. M. M.; BARRERA-BASSOLS, N. A etnoecologia: uma ciência pós-normal que estuda as sabedorias tradicionais. Desenvolvimento e Meio ambientes. v. 20, p. 31-45, 2009.

VINUTO, J. A amostragem em bola de neve na pesquisa qualitativa: um debate em aberto. Temáticas, v.22, n. 44, p. 203-220, 2014. 